\title{
Editorial
}

Digestion

\section{Propofol-Based Sedation in Gastrointestinal Endoscopy: Getting Safer and Safer}

\author{
Dieter Schilling \\ Department of Gastroenterology, Diakonissenkrankenhaus Mannheim GmbH, Mannheim, Germany
}

Deep sedation for endoscopic procedures has become an increasingly used option. However, because of impairment in patient response, this technique also bears an increased risk of adverse events. Sedation-associated complications in gastrointestinal endoscopy show incidences between 0.1 and $3.6 \%$ [1-3]. Sedation is therefore a substantial cause for complications in gastrointestinal endoscopy and has to be focused on critically by the gastroenterologists who perform sedation in gastrointestinal endoscopy as the "non-anaesthesiologist administration of propofol' (NAAP) procedure. Many anaesthesiologists and also the ASA expressed their concerns 'that individuals, who are not anaesthesia professionals, may not recognize that sedation and general anaesthesia are on continuum, and thus deliver levels of sedation that may in fact be general anaesthesia without having the training and the experience to respond appropriately' [4]. Recently, 21 national societies of anaesthesiology in Europe signed a consensus statement confirming that propofol should be administered only by those trained in the administration of general anaesthesia [5]. The German Society of Anaesthesiology did not sign this paper. The German anaesthesiologists took part in the guideline conference of sedation in gastroenterological endoscopy [6]. One result of this guideline conference was the structured 3-day train- ing course 'Sedation and Emergency Management in Endoscopy for Endoscopy Nurses and Assisting Personnel' for nurses to be able to perform the sedation supervised by the endoscopist. Several trials confirm that adequately trained nurses supervised by endoscopists are able to safely administer propofol sedation for endoscopy procedures [7-9]. In a recently published trial, we were able to demonstrate that these training courses for nurses improved structures in gastrointestinal endoscopy with respect to patient safety [10].

A recent analysis showed that the use of anaesthesia services for colonoscopy is associated with a somewhat higher frequency of complications, specifically, aspiration pneumonia [9].

NAAP for endoscopic procedures is safe when performed by personnel properly trained in airway handling and sedation with propofol. This could be proven by the analysis of a prospective complication registry of 388,404 gastrointestinal endoscopic procedures in the typical NAAP manner $[11,12]$. In this context the study by Müller et al. [13] should be seen.

In a recent study [10], the safety and efficacy of routine insertion of a special soft nasopharyngeal airway tube in longer lasting upper and lower gastrointestinal endoscopy have been analysed. The authors could demonstrate

\section{KARGER}

E-Mail karger@karger.com

www.karger.com/dig (c) 2014 S. Karger AG, Base

0012-2823/14/0894-0272\$39.50/0
Dieter Schilling, MD

Department of Gastroenterology

Diakonissenkrankenhaus Mannheim GmbH

Speyerer Strasse 91-93, DE-68163 Mannheim (Germany)

E-Mail Dieter.Schilling@ diakonissen.de 
that this nasopharyngeal airway tube was able to significantly reduce the frequency of hypoxemia, and also hypotension was seen less often. This easy manoeuvre is effective and has only a minor risk for nasopharyngeal injury in patients without deviation of the nasal septum, without anticoagulants or non-steroidal anti-inflammatory drugs and not being ASA IV.

This study [10] shows that sedation in gastrointestinal endoscopy is becoming safer, even if the technique examined is only fitting in about two thirds of all patients who underwent an endoscopic procedure. This study is a pilot study and the data have to be confirmed by multicentre trials. For planning these studies, we now know that we do not have to assume a high complication rate of this soft airway tube. Maybe more patients will participate than in this recent study.

A high percentage of gastroenterologists in Germany want to be responsible for sedation and perform NAAP, which is why we have to perform such studies!

\section{References}

1 Heuss LT, Schnieper P, Drewe J, Pflimlin E, Beglinger C: Safety of propofol for conscious sedation during endoscopic procedures in high-risk patients - a prospective, controlled study. Am J Gastroenterol 2003;98:17511757.

2 Wehrmann T, Riphaus A: Sedation with propofol for interventional endoscopic procedures: a risk factor analysis. Scand J Gastroenterol 2008;43:368-374.

-3 Rex DK, Deenadayalu VP, Eid E, Imperiale TF, Walker JA, Sandhu K, Clarke AC, Hillman LC, Horiuchi A, Cohen LB, Heuss LT, Peter S, Beglinger C, Sinnott JA, Welton T, Rofail M, Subei I, Sleven R, Jordan P, Goff J, Gerstenberger PD, Munnings H, Tagle M, Sipe BW, Wehrmann T, Di Palma JA, Occhipinti KE, Barbi E, Riphaus A, Amann ST, Tohda G, McClellan T, Thueson C, Morse J, Meah $\mathrm{N}$ : Endoscopist-directed administration of propofol: a worldwide safety experience. Gastroenterology 2009;137:1229-1237.

4 ASA statement on granting privileges for administration of moderate sedation to practitioners, 2010 (http://asanq.org).

5 Perel A: Non-anaesthesiologist should not be allowed to administer propofol for procedur- al sedation: a Consensus Statement of $21 \mathrm{Eu}$ ropean National Societies of Anaesthesia. Eur J Anaesthesiol 2011;28:580-584.

-6 Riphaus A, Wehrmann T, Weber B, Arnold J, Beilenhoff $U$, et al: $S 3$ guidelines: sedation in gastrointestinal endoscopy (in German). Z Gastroenterol 2008;46:1298-1330.

-7 Tahda G, Higashi S, Wakahara S, et al: Propofol sedation during endoscopic procedures safe and effective administration by registered nurses supervised by endoscopists. Endoscopy $2006 ; 38: 360-367$.

-8 Jensen JT, Vilman P, Horsted T, et al: Nurseadministered propofol sedation for endoscopy: a risk analysis during implementation phase. Endoscopy 2011:43:716.

-9 Schilling D, Rosenbaum A, Schweizer S, Richter H, Rumstadt B: Sedation with propofol for interventional endoscopy by trained nurses in high-risk octogenarians: a prospective, randomized, controlled study. Endoscopy 2009; 41:295-298.

10 Schilling D, Leicht K, Beilenhoff U, Kern Waechter E, Kallinowski B, Labenz J, Weiss C, Büttner S, Riphaus A: Impact of S3 training courses 'Sedation and Emergency Management in Endoscopy for Endoscopy Nurses and
Assisting Personnel' on the process and structure quality in gastroenterological endoscopy in practices and clinics: results of a nationwide survey. Z Gastroenterol 2013;51:619-627.

11 Behrens A, Labenz J, Schuler A, Schröder W, Rünzi M, Steinmann RU, de Mas CR, Kreuzmayr A, Barth K, Bahr MJ, Burmester E, Erckenbrecht JF, Frieling T, Dumoulin FL, Pfaffenbach B, Schepp W, Schneider A, Kleber G, Meiborg M, Böhm S, Dietrich C, Dietrich CF, Gottschalk U, Ell C: How safe is sedation in gastrointestinal endoscopy? A multicentre analysis of 388,404 endoscopies and analysis of data from prospective registries of complications managed by members of the Working Group of Leading Hospital Gastroenterologists (ALGK) (in German). Z Gastroenterol 2013;51:432-436.

12 Cooper GS, Kou TD, Rex DK: Complications following colonoscopy with anesthesia assistance: a population-based analysis. JAMA Intern Med 2013;173:551-556.

$\checkmark 13$ Müller M, Wehrmann T, Eckardt AJ: Prospective evaluation of the routine use of a nasopharyngeal airway (Wendl tube) during endoscopic propofol-based sedation. Digestion 2013, Epub ahead of print.
Propofol-Based Sedation in Gastrointestinal Endoscopy: Getting Safer and Safer 